University of Louisville

ThinkIR: The University of Louisville's Institutional Repository

$5-2004$

\title{
A clinical comparison of decalcification following orthodontic treatment using composite resin and reinforced modified glass ionomer cements.
}

Jennifer L. Butterfoss 1976-

University of Louisville

Follow this and additional works at: https://ir.library.louisville.edu/etd

\section{Recommended Citation}

Butterfoss, Jennifer L. 1976-, "A clinical comparison of decalcification following orthodontic treatment using composite resin and reinforced modified glass ionomer cements." (2004). Electronic Theses and Dissertations. Paper 191.

https://doi.org/10.18297/etd/191

This Master's Thesis is brought to you for free and open access by ThinkIR: The University of Louisville's Institutional Repository. It has been accepted for inclusion in Electronic Theses and Dissertations by an authorized administrator of ThinkIR: The University of Louisville's Institutional Repository. This title appears here courtesy of the author, who has retained all other copyrights. For more information, please contact thinkir@louisville.edu. 


\title{
A CLINICAL COMPARISON OF DECALCIFICATION FOLLOWING ORTHODONTIC TREATMENT USING COMPOSITE RESIN AND REINFORCED MODIFIED GLASS IONOMER CEMENTS
}

\author{
By \\ Jennifer L. Butterfoss \\ B.B.A., College of William and Mary, 1998 \\ D.D.S., Virginia Commonwealth University School of Dentistry, 2002
}

\author{
A Thesis \\ Submitted to the Faculty of the \\ Graduate School of the University of Louisville \\ In Partial Fulfillment of the Requirements \\ for the Degree of
}

Master of Science

Program in Oral Biology

School of Dentistry

University of Louisville

Louisville, Kentucky

May 2004 


\title{
A CLINICAL COMPARISON OF DECALCIFICATION FOLLOWING ORTHODONTIC TREATMENT USING COMPOSITE RESIN AND REINFORCED MODIFIED GLASS IONOMER CEMENTS
}

\author{
By \\ Jennifer L. Butterfoss \\ B.B.A., College of William and Mary, 1998 \\ D.D.S., Virginia Commonwealth University School of Dentistry, 2002
}

A Thesis Approved on

10 March 2004

by the following Thesis Committee:

Baxter E. Johnson, D.D.S., M.S.

Thesis Director

David Tasman, D.M.D.

James P. Scheetz, M.A., Ph.D. 


\section{DEDICATION}

I would like to dedicate this Masters Thesis to my future husband, Dan for all of his support over the past four years. He has stood by me throughout dental school and during our years apart due to my residency. I also would like to dedicate this to my parents who have been the foundation and inspiration for my success in every aspect of my life. They have supported me in every way possible and have been my constant role models. 


\section{ACKNOWLEDGEMENTS}

I am indebted to the following individuals for their assistance with this project:

Dr. Ed Johnson, Thesis Committee Member and Chairman of the Department of Orthodontics, for his enthusiasm and support on this research project and on my education in orthodontics.

Dr. David Tasman, Thesis Committee Member and faculty of the Department of Orthodontics, for his aid as a committee member on this project and for all of his daily advice and assistance in the clinic.

Dr. James Scheetz, Chief Statistician, for his assistance with conception and interpretation of the statistics involved in the preparation for this thesis. 


\title{
ABSTRACT \\ A CLINICAL COMPARISON OF DECALCIFICATION FOLLOWING ORTHODONTIC TREATMENT USING COMPOSITE RESIN AND REINFORCED MODIFIED GLASS IONOMER CEMENTS
}

\author{
Jennifer L. Butterfoss, D.D.S.
}

10 March 2004

Background and Significance: Even with the advent of direct bonding, decalcification remains a problem in orthodontics today. Glass ionomer cements have been used in dentistry for fluoride release for years and may have beneficial use in orthodontics to reduce decalcification.

Purpose: This study aims to evaluate the incidence in decalcification between orthodontic patients bonded with either composite resin or resin modified glass ionomer (RMGI) cements. Varying levels of hygiene and treatment time were also evaluated.

Methods: Intraoral pre-treatment and post-treatment photographs from patients bonded with either RMGI or composite resin were evaluated for changes in decalcification.

Patients were treated by the same practitioner and the data was gathered retrospectively. Results: Patients bonded with glass ionomer cement demonstrated significantly less decalcification than those bonded with composite resin. Treatment time and hygiene were not significant.

Conclusions: Glass ionomer cements used for direct bonding reduce decalcification in orthodontic patients on a fluoride protocol. 


\section{TABLE OF CONTENTS}

PAGE

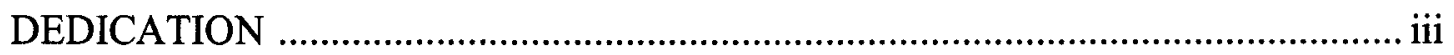

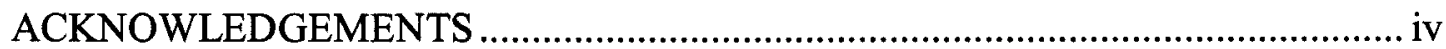

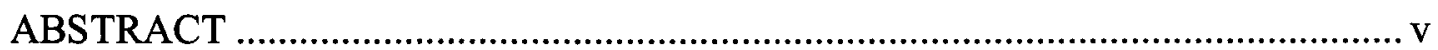

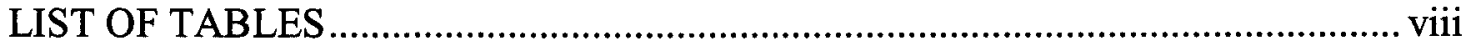

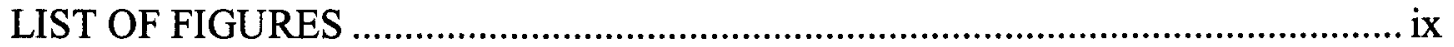

\section{CHAPTER}

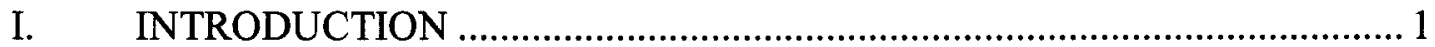

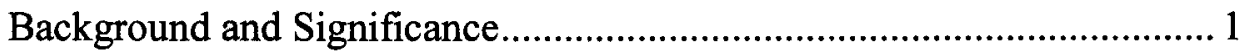

Study Objectives ................................................................................. 3

Study Hypotheses.................................................................................... 3

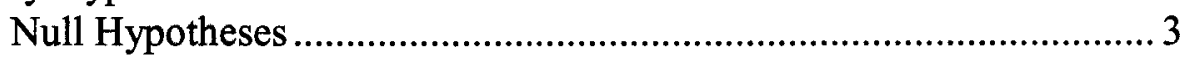

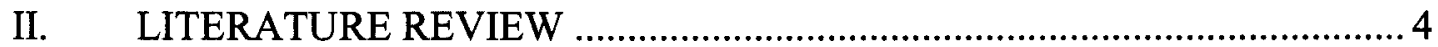

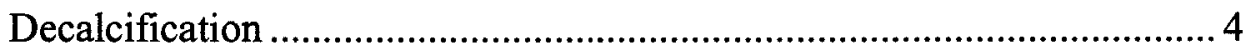

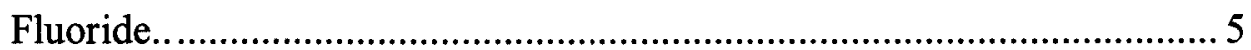

Glass Ionomer Cements ......................................................................... 6

Previous Studies Evaluating Decalcification and Glass Ionomer.............. 9

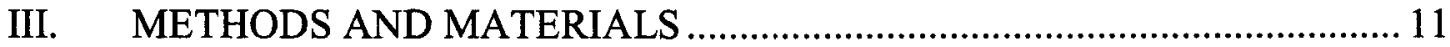

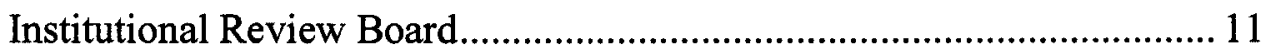

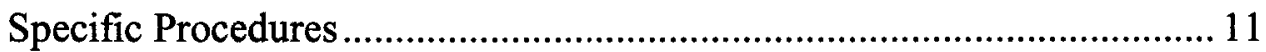

Statistical Analysis ............................................................................ 14

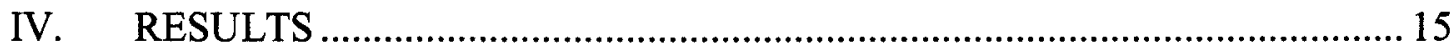

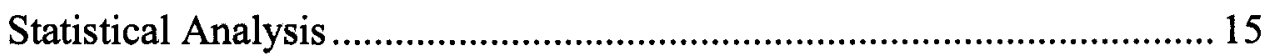

Univariate ANOVA with Tukey Post-hoc .......................................... 15

Intra-rater Reliability.................................................................... 16

Box Plots of Data Collected ............................................................. 17

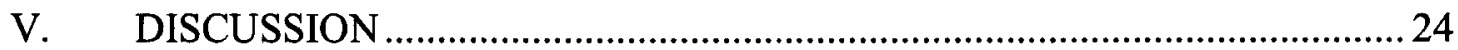

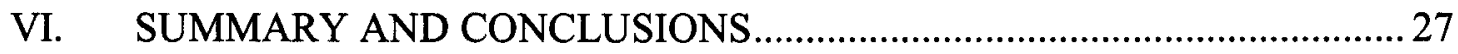

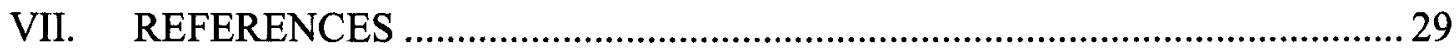


VIII. CURRICULUM VITAE.

.32 


\section{LIST OF TABLES}

TABLE

PAGE

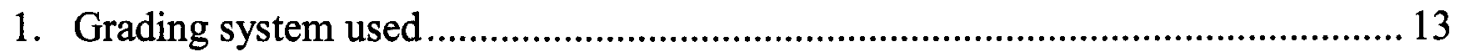

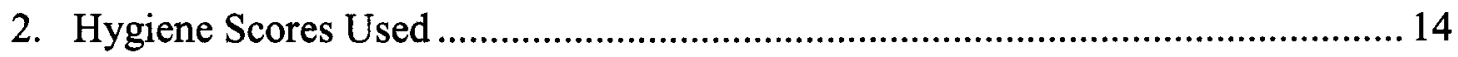

3. Univariate Analysis of Variance: Between Subjects Effects................................ 15

4. Mean Decalcification Change Between Cement Types ......................................... 16

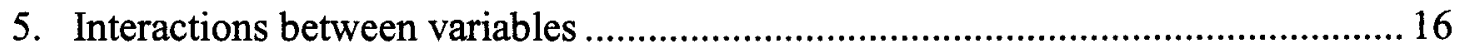

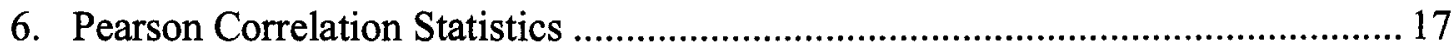

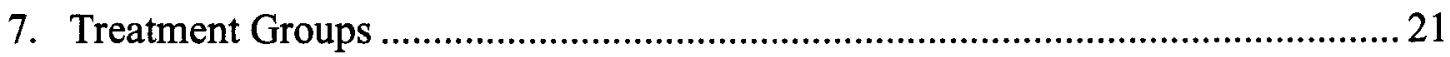




\section{LIST OF FIGURES}

FIGURE

PAGE

1. Clinical Decalcification following Orthodontic treatment ................................. 4

2. Fuji Ortho LC Resin Modified Glass Ionomer ................................................... 8

3. Box plot: Decalcification Change vs. Type of Cement ……….............................. 17

4. Patient in Composite Resin Cement Group...................................................... 18

5. Patient in Composite Resin Cement Group........................................................ 19

6. Patient in Composite Resin Cement Group........................................................ 19

7. Patient in Glass Ionomer Cement Group........................................................... 19

8. Patient in Glass Ionomer Cement Group ........................................................... 19

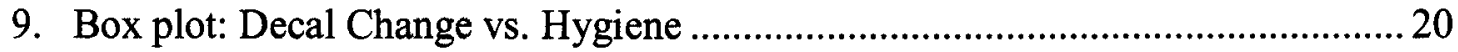

10. Box plot: Decal Change vs. Treatment Months.................................................... 21

11. Line Graph: Decal Change for Treatment Months and Cement Type ……...........22

12. Line Graph: Decal Change for Hygiene and Cement Type ……........................2 23 


\section{CHAPTER I \\ INTRODUCTION}

\section{Background and Significance}

A major advancement in orthodontics evolved when orthodontic brackets were first bonded directly to the facial surface of teeth. Prior to direct bonding, orthodontists had to custom fit bands on each tooth. This process was time consuming for the orthodontist and uncomfortable for the patient (Meehan, Foley and Mamandras, 1999). By the 1980 's, direct bonding brackets with composite resin cement was widely accepted by the orthodontic community. Direct bonding increases accessibility for removing plaque, reduces soft tissue irritation and hyperplastic gingiva, facilitates placing attachments on partially erupted teeth, and creates a more esthetic appearance (Bishara, VonWald, Laffoon and Jakobsen, 2000). The process of bonding orthodontic brackets with a composite resin cement requires that the teeth be prepared with an acid etch to initially decalcify the enamel. During bonding, the tooth must remain completely dry to prevent saliva contamination (Silverstone, Hicks and Featherstone, 1985). A major concern of bonding with composite resin is the tooth surface surrounding the bracket which is prone to plaque retention and decalcification. Decalcification most commonly appears as a white discoloration on the tooth surface in the area around the bracket (Gaworski, Weinstein, Borislow and Braitman, 1999). 
Decalcification is a major concern in orthodontics for both the patient and the practitioner. Even if the teeth are aligned to standards acceptable to the American Board of Orthodontics, patients are disappointed with the results if decalcification is present. Decalcification is caused by prolonged adhesion of plaque on the surface of the tooth with subsequent demineralization of the enamel. Poor oral hygiene due to lack of patient compliance and reduced access to the tooth surface is a problem during orthodontic treatment. For many years, practitioners and researchers have sought out to eliminate or reduce this occurrence.

Several in vitro studies (Vorhies, Donly, Staley and Wefel, 1998; Coonar, Jones and Pearson, 2001) have been conducted to evaluate the effectiveness of fluoride release from resin modified glass ionomer cements when used to direct bond orthodontic brackets. These studies demonstrated a decrease in decalcification in the resin modified glass ionomer samples. However, in vivo studies have failed to find a difference in decalcification between cement samples. In most of the in vivo studies, there was no fluoride regimen used other than fluoridated toothpaste, and the sample sizes were quite small. This study will evaluate whether the inclusion of a daily fluoride rinse to recharge the cement in cases treated with glass ionomer will exhibit less decalcification than those treated with conventional composite resin.

Future research should focus on increasing the number of patients in the study groups, implementing daily fluoride rinses to "recharge" the glass ionomer cements, and evaluating other factors such as diet, enamel quality, and salivary content that may lead to decalcification. 


\section{$\underline{\text { Study Objectives }}$}

The primary objective of this study is to evaluate the presence of decalcification in patients following orthodontic treatment when using two different types of cement to directly bond orthodontic brackets. This study will ascertain if a fluoride releasing cement such as resin modified glass ionomer will reduce the incidence of decalcification during orthodontic treatment. The secondary objective of this study is to correlate the incidence of decalcification with patient oral hygiene and total treatment time.

\section{Study Hypotheses}

This retrospective study examined decalcification in orthodontic patients bonded with two different cements, a composite resin cement and a glass ionomer cement. Additional data was gathered from patient charts on hygiene and orthodontic treatment time to evaluate the effects of these factors on decalcification. Resin modified glass ionomer will reduce the incidence of decalcification during orthodontic treatment.

\section{Null Hypotheses:}

1. There is no significant difference between the incidence of decalcification when using resin modified glass ionomer and composite resin cement to directly bond orthodontic brackets.

2. There is no significant difference between the incidence of decalcification in patients with varying levels of oral hygiene.

3. There is no significant difference between the incidence of decalcification in patients with varying lengths of treatment time. 


\section{CHAPTER II}

\section{LITERATURE REVIEW}

\section{Decalcification}

The early appearance of dental caries appears as a white discoloration on the surface of the tooth. The clinical appearance of the decalcification is caused by an optical phenomenon due to subsurface loss of tissue (Gorelick, Geiger \& Gwinnett, 1982). The main cause of decalcification is known to be excessive dental plaque on the surface of the tooth. In addition to retention of plaque, oral hygiene and varied "resistance levels" have also been identified as factors in decalcification during orthodontic treatment (Trimpeneers and Dermaut, 1996). According to Gorelick et al, the maxillary incisors are the most common location for decalcification (1982).

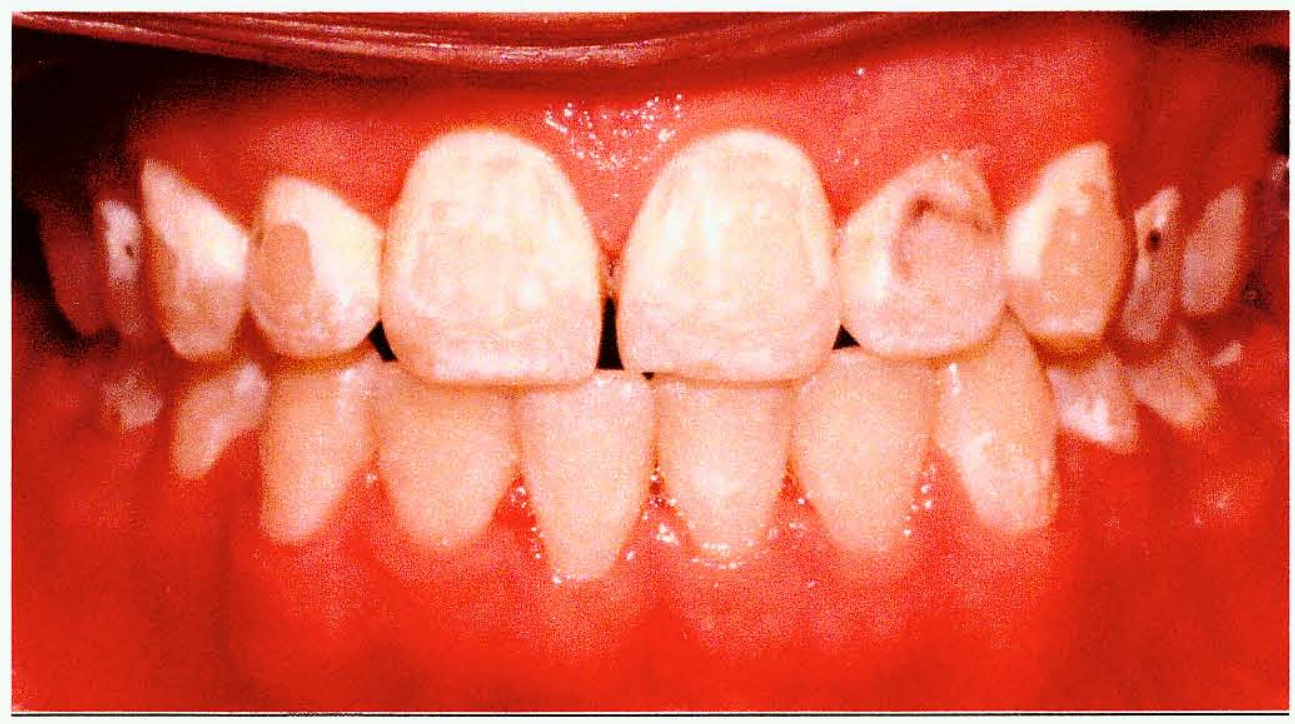

Figure 1. Clinical Decalcification following Orthodontic treatment 
The presence of orthodontic appliances can physically alter the microbial environment causing proliferation of the facultative bacterial populations such as Streptococcus mutans (Mattingly, Sauer, Yancey and Arnold, 1983). Areas of superficial decalcification can be seen on a scanning electron microscope at the bracket tooth junction as soon as one week after banding. However, it has been demonstrated that by introducing fluoride in small quantities, the rate and degree of remineralization can increase due to encouraging the regrowth of the exhausted crystals (O'Reilly and Featherstone, 1987).

\section{Fluoride}

Fluoride has long been known to prevent the decalcification of enamel by making the enamel more acid resistant (Sturdevant, 1995). Several methods have been tested to increase the amount of fluoride available to the dentition. Topical fluoride has been shown to decrease the size of existing white spot lesions and the formation of new lesions. Featherstone found, in a review of past research, that the primary mechanisms of fluoride action are topical (2003). He summarized the contribution of fluoride as inhibiting demineralization, enhancing remineralization and inhibiting plaque bacteria. The fluoride ion combines with calcium and phosphate ions in the saliva to increase the precipitation of fluorapatite into tooth structure. Fluorapatite is insoluble and replaces the soluble salts that were lost during bacterial-mediated demineralization. This process both protects sound tooth structure and repairs incipient carious lesions. Fluoride also plays an antibacterial role in the prevention of caries. The fluoride ion in low concentrations inhibits the production of an enzyme that promotes bacterial 
adhesion. In high concentrations, such as with topical fluoride treatments, the fluoride ion suppresses the growth of streptococci mutans (Sturdevant, 1995).

Many techniques have been employed to attempt to reduce the incidence of decalcification. A prospective clinical trial was completed in the United Kingdom using stannous fluoride-releasing elastomeric modules to compare decalcification against conventional elastomerics (Banks, Chadwick, Asher-McDade, and Wright, 2000). This study showed a significant difference in decalcification between the two groups with the fluoridated elastomeric group exhibiting less decalcification.

Horowitz (1980) evaluated past research and found a 30 percent reduction in caries with use of a fluoride mouth rinse. O'Reilly and Featherstone (1987) demonstrated that orthodontic patients can benefit from a fluoride mouth rinse. Several types of fluoride rinses can be found on the market today. Sodium fluoride rinses are available as a .02 per cent weekly rinse as well as a .05 per cent daily rinse. The lower concentration daily rinse is sufficient to increase both salivary and plaque fluoride levels to a level that inhibits demineralization (Hind, 1999). In addition, stannous fluoride gels can be used at a 0.4 per cent concentration. This concentration has the same success rate as the .05 per cent sodium fluoride according to a 1993 study by Boyd.

\section{Glass Ionomer Cements}

Glass ionomer materials have been used in dentistry for years as sealants, liners and cements in an effort to release fluoride to underlying dentin. In recent years, glass ionomers have entered the orthodontic marketplace as cement for direct bonding of 
brackets. Glass ionomer cements have several advantages including the ability to bond in a wet field and the ability to release fluoride continually to the surrounding tooth structure. A major disadvantage to the use of glass ionomers is the frequency of bracket failure. In a clinical study comparing glass ionomer and resin cements, the authors concluded that the use of glass ionomer cements for orthodontic bonding significantly increases the risk of bond failures during treatment (Norevall, Marcusson \& Persson,, 1996). Similar results were found in a study that compared a two-paste resin with a chemically cured glass ionomer cement (Miguel, Almeida \& Chevitarese, 1995). In this clinical trial, glass ionomer had a statistically significant increased failure rate of $51 \%$ compared with the $8 \%$ failure rate of the resin.

To combine the desirable properties of composite bond strength and glass ionomer fluoride release, resin modified glass ionomers were introduced. Resinmodified glass ionomers have a dual cure setting reaction consisting of the acid base reaction from traditional glass ionomer cements and the polymerization reaction induced either chemically or by visible light (Fricker, 1998). In an in vitro study, Rix, Foley and Mamandras (2001) evaluated the bond strengths of several cements. They found that the composite resin control had significantly greater bond strength than the glass ionomer (20.9 MPa versus 13.57 MPa). However, both adhesives have clinically acceptable bond strengths. Fricker found no statistical significance between resin modified glass ionomer and composite resin in a 12 month clinical study (1998). In the absence of occlusal interferences, Fricker concluded that resin modified glass ionomer cements are satisfactory adhesives for the direct bonding of orthodontic brackets.

According to Newman, Newman and Sengupta (2001), increased bond strength can be 
achieved by conditioning slightly moist teeth with $10 \%$ polyacrylic acid as opposed to bonding to an unconditioned tooth. Conditioning the tooth removes bacterial plaque and remnants of the organic pellicle and increases the bonding surface area.

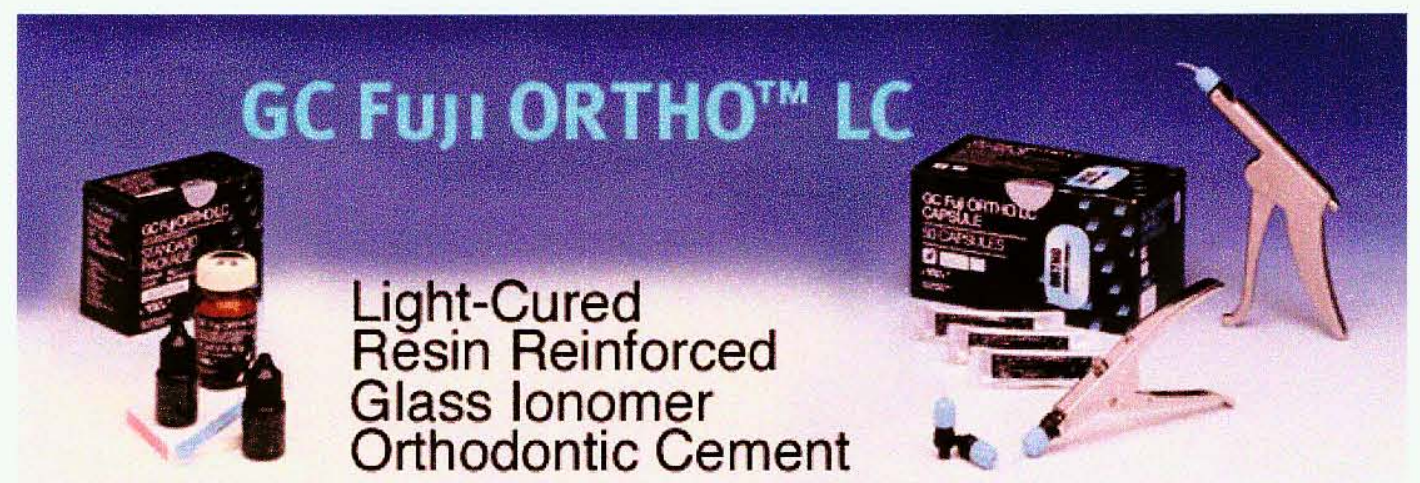

Figure 2. Fuji Ortho LC Resin Modified Glass ionomer (www.fuji.com)

Fuji Ortho LC is one such RMGIC that claims less technique sensitivity than composite resins due to the ability to bond in a wet field. Fuji Ortho LC involves three reactions for complete setting. These reactions are as follows: a glass ionomer acidbase reaction, a light-activated polymerization of HEMA and two other polymers to form a polyHEMA matrix, and a self-cure of the resin monomers (Bishara, Olsen, Damon and Jakobsen, 1998). Fuji Ortho LC also claims that it can release fluoride and decrease the incidence of decalcification. Fluoride is released by a reaction between the polyacid and alumino silicate glass causing a release of the $\mathrm{Al} 3+, \mathrm{Ca} 2+$, and $\mathrm{F}$ ions (Sturdevant, 1995). The fluoride release can be continually "recharged" by introducing fluoride into the oral environment in the form of a rinse or paste. This ability of glass ionomer to absorb fluoride and reconstitute itself may assist in the decreased incidence of white spot decalcification around brackets (Gaworski et al, 1999). 
An additional benefit of using glass ionomer cements was discussed by Kusy in a 1994 letter to the Journal of Clinical Orthodontics editor. He recommended the use of glass ionomer cements in order to reduce damage to the teeth that occurs with debonding composite bonding resins because they are acid etched into the tubules of the enamel.

\section{$\underline{\text { Previous Studies Evaluating Decalcification and Glass Ionomer Cements }}$}

In a 1998 study, extracted teeth were bonded with both RMGI and composite and brushed twice daily (Vorhies, Donly, Staley and Wefel). According to the authors, "Teeth bonded with the hybrid glass ionomer cements, both brushed and non-brushed, demonstrated significantly smaller enamel lesions adjacent to the bracket base than teeth bonded with a composite resin that were brushed twice daily (p647)." Coonar et al in 2001 evaluated three cements to compare fluoride release. Their results showed that Fuji-Ortho L.C. released the greatest amount of fluoride when compared with Limerik glass and Concise. The study also found that when "recharged" with $2 \%$ Sodium fluoride, Fugi-Ortho L.C. continued to release fluoride.

In addition, in vivo studies have been conducted to evaluate the fluoride release and bond strengths of the two types of cements. In a 1998 clinical paper by Charles, a comparison was made between clinics that use solely glass ionomer cements and those using composite cements for bracket bonding. Charles found a $6.5 \%$ decalcification rate in his clinic compared to the reported $50 \%$ average found in other clinics. In addition, he found that the bonding is quicker and easier with the glass ionomer because there is no need to maintain moisture control. As far as bond failure, Charles found an 
acceptable rate of $3 \%$ for the resin modified glass ionomer, Fuji Ortho LC. In a split mouth prospective clinical trial, Gaworski et al evaluated decalcification and bond strength in 16 patients with brackets bonded with composite and RMGI (1999). The investigation revealed that the brackets bonded with composite resin had fewer bond failures than those bonded with RMGIC and that both cements had equal decalcification. However, this study had a small sample size and did not have a system in place for fluoride "recharge". In 1999, Millet, Nunn, Welbury and Gordon conducted a split mouth study comparing decalcification using glass ionomer and composite resin. The conclusion from the study was that there was no significant difference between the two cements with respect to decalcification. 


\section{CHAPTER III \\ METHODS AND MATERIALS}

\section{Institutional Review Board}

This study protocol was reviewed and approved by Serge A. Martinez, M.D., JD., Chairman of the University of Louisville's Human Studies Committee. In a letter dated October 27, 2003, this study (257-03) was approved through the Expedited Review Procedure, Category 7. The study was approved through October 27, 2004.

\section{$\underline{\text { Specific Procedures }}$}

Two groups of 100 consecutively treated, comprehensive orthodontic cases from a private practice were evaluated for decalcification both before and after treatment. Group 1 consisted of 100 consecutive cases started December 1996 through August 1997. In this group, bonded brackets were placed with chemical cured composite resin cement (Accubond, GAC). Group 2 consisted of 100 consecutive full treatment cases starting in December 1998 though August 1999. In this second group, the bonded brackets were placed with light cured modified reinforced glass ionomer cement (Fuji Ortho LC, GC Corp). In both groups, 4 quadrants were bonded with a stainless steel bracket (GAC MINI TWIN). Five (5\%) of the Group II patients had the maxillary arch bonded with a clear resin bracket (Spirit MB, ORMCO). 
Patients in both groups were given a fluoride rinse. It was demonstrated in vivo in 1987 by O'Reilly and Featherstone that daily brushing with fluoridated toothpaste and rinsing with a fluoridated mouth rinse inhibited demineralization and or promoted remineralization more that brushing alone.

The bonding procedure for Group I was as follows: Enamel surfaces were thoroughly brushed and cleaned and all teeth were etched with a $40 \%$ phosphoric acid gel for 45 seconds. The isolated teeth were rinsed and air-dried. An unfilled resin bonding agent was applied to the prepared surfaces. The 2-paste composite resin cement was mixed and applied to the bracket. The bracket was placed on the tooth surface and positioned. Excess cement was removed with an explorer and the brackets were allowed to rest for 5 minutes. After complete cure, a nickel-titanium arch wire was ligated with elastic ties. The bond procedure for Group II was as follows: Enamel surfaces were thoroughly brushed and cleaned and all teeth were conditioned for ten seconds with $10 \%$ polyacrylic acid. The teeth were rinsed thoroughly and left moist. A Fuji Ortho LC capsule was triturated and the cement was delivered to the bracket with a dispensing syringe. The brackets were placed and positioned. Excess cement was removed with an explorer. The cement was cured for 40 seconds, 10 seconds per bracket edge. Following complete curing, a nickel-titanium arch wire was ligated with elastic ties.

Pre-treatment and post-treatment intraoral photos of each patient in the study were collected and randomized. All photos were taken on the same Kodak camera and included one anterior and two buccal photos for each patient per time period. Six anterior maxillary teeth from canine to canine were evaluated for the presence or 
absence of decalcification. A score from 0 to 6 was given to each patient both before and after treatment. A score of zero indicated no decalcification and a score of 6 indicated decalcification on all six teeth (Table 1). A delta score was calculated from the pre-treatment and post- treatment scores to show the amount of decalcification that occurred during orthodontic treatment.

In addition, the following data was collected from each chart: Age, sex and total treatment time. A standardized hygiene evaluation was performed at each patient visit. The following rating criteria were used: $1=$ no visible plaque; $2=$ plaque on 3 or less brackets; 3 = plaque on 4 or more brackets; $4=$ plaque on most brackets and some teeth; $5=$ plaque on most brackets and teeth (Table 2).

\section{Table 1.}

Grading system used.

\begin{tabular}{|c|c|}
\hline score & Description \\
\hline 0 & No decalcification on teeth \\
\hline 1 & Decalcification on one tooth \\
\hline 2 & Decalcification on two teeth \\
\hline 3 & Decalcification on three teeth \\
\hline 4 & Decalcification on four teeth \\
\hline 5 & Decalcification on five teeth \\
\hline 6 & Decalcification on all six teeth \\
\hline
\end{tabular}


Table2.

Hygiene Scores used.

\begin{tabular}{|c|l|}
\hline \multicolumn{2}{|c|}{ I)(scriplion } \\
\hline 1 & No visible plaque \\
\hline 2 & Plaque on 3 or less brackets \\
\hline 3 & Plaque on 4 or more brackets \\
\hline 4 & Plaque on most brackets and some teeth \\
\hline 5 & Plaque on most brackets and teeth \\
\hline
\end{tabular}

\section{$\underline{\text { Statistical Analysis }}$}

A univariate analysis of variance with a Tukey post-hoc test was performed to determine statistical differences between the factors that may contribute to decalcification. A Pearson correlation test was performed on the examiner's responses for the images that had been evaluated in duplicate to evaluate intra-rater reliability. All resultant data was analyzed with the assistance of the computer-generated statistical software package Statistical Program for the Social Sciences (SPSS) for Windows, Version 11.

Consultation on all data entry and other necessary statistical testing requirements were coordinated through Dr. James P. Scheetz, the chief statistician for this study. 


\section{CHAPTER IV}

\section{RESULTS}

\section{$\underline{\text { Statistical Analysis }}$}

\section{Univariate Analysis of Variance with Tukey Post-hoc:}

Data was analyzed with a univariate analysis of variance and post-hoc Tukey test (Table 3). Three independent variables were compared with the dependent variable, change in decalcification. The three independent variables were cement, hygiene and treatment months. The only independent variable that was significant at the .05 level was the type of cement. Table 4 demonstrates the mean decalcification for the two different types of cements. The glass ionomer group exhibited over 2 times less decalcification than the composite group.

\section{Table 3.}

Univariate Analysis of Variance: Between Subjects Effects

\begin{tabular}{|c|c|c|}
\hline Varriable & Vlan S(puarc & Significance \\
\hline Cement & 13.645 & $.004^{*}$ \\
\hline Hygiene & 1.005 & .604 \\
\hline $\begin{array}{c}\text { Treatment } \\
\text { Months }\end{array}$ & 2.841 & .160 \\
\hline
\end{tabular}

\footnotetext{
* Significant at the .05 level.
} 
Table 4.

Mean Decalcification Change between Cement Types

\begin{tabular}{|c|c|c|}
\hline ( cmont & Ilean & Stl. I) \\
\hline Composite & 1.45 & 1.625 \\
\hline $\begin{array}{c}\text { Glass } \\
\text { Ionomer }\end{array}$ & .66 & .876 \\
\hline Total & 1.02 & 1.336 \\
\hline
\end{tabular}

There were three two way interactions and one three way, however none of the interactions were significant (Table 5).

Table 5.

Interactions between variables.

\begin{tabular}{|c|c|c|}
\hline Intcraction & Mean Sipuare & Signiticance \\
\hline Tx months* hygiene & 2.462 & .148 \\
\hline Tx months* cement & .458 & .838 \\
\hline Hygiene* cement & .534 & .805 \\
\hline Tx months* hygiene* cement & 1.287 & .557 \\
\hline
\end{tabular}

\section{Intra-rater Reliability}

Pearson correlation statistics were used to analyze the intra-rater reliability.

Twenty of the intraoral photo sets were evaluated twice by the examiner. Photo sets were chosen randomly and evaluated by the examiner at separate time intervals. Both sets of images were scored for decalcification using the same criteria as afore mentioned in Table 1. Based on the Pearson tests, the relationships between scores at both time intervals were significant at the .01 level (Table 6). 


\section{Table 6.}

Pearson Correlation Statistics: Correlation of Time 1 and Time 2.

\begin{tabular}{|c|l|l|}
\hline Time & Pearson Correlation & Sig. (2-tailed) \\
\hline Time 1 & .983 & .000 \\
\hline Time 2 & .983 & .000 \\
\hline
\end{tabular}

* Numbers shown in red mean difference is significant at the .01 level (2-tailed)

\section{Box Plots of Data Collected}

Figure 3 shows the box plot graphical representation of the change in decalcification for each type of cement used. The composite resin cement yielded more decalcification when compared to the composite resin cement. Decalcification change of 0 shows that there is no decalcification change (Table 1 ).

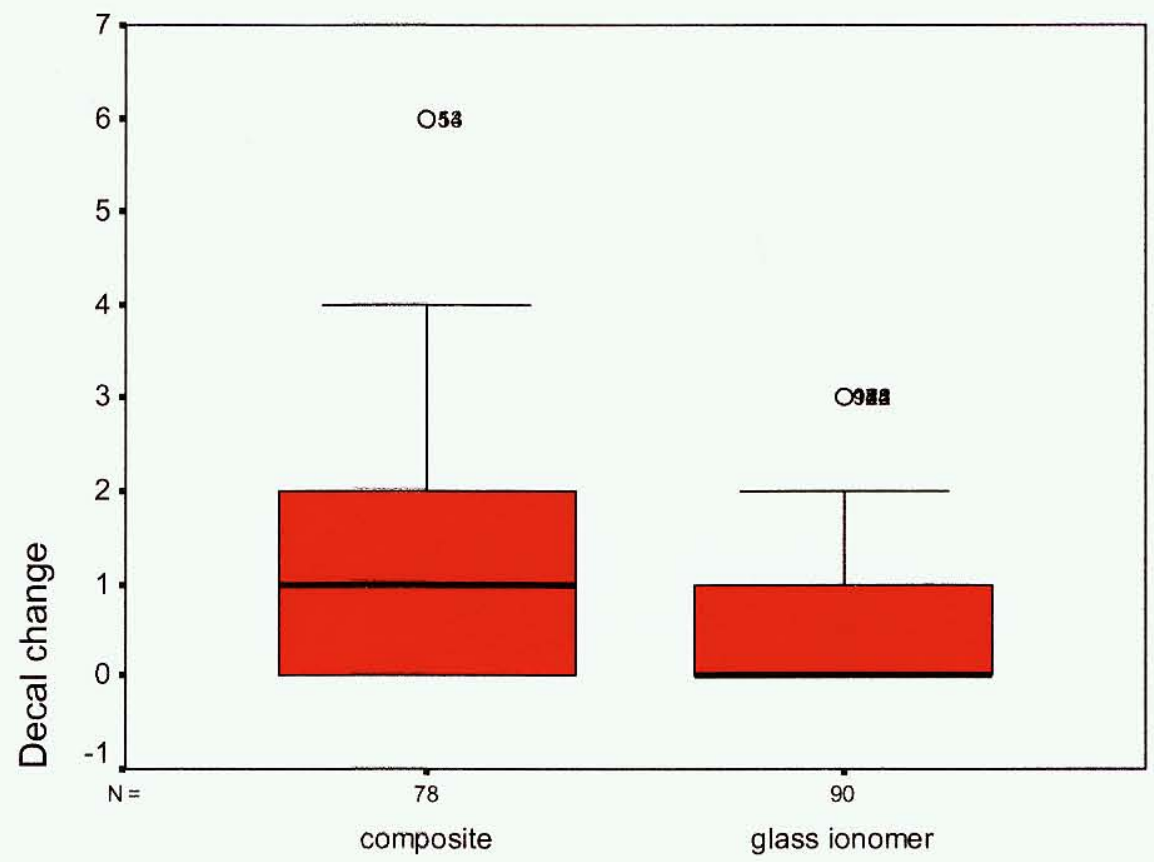

\section{CEMENT}

Figure 3. Box plot: Decalcification change vs. type of cement. 
There were several outliers for each cement type. After the completion of data collection, it was possible to delve further into the cause of extreme decal in several patients. The greatest amount of decalcification seen in the composite group was a score of 6 , meaning decalcification on all six anterior teeth. The greatest amount of decalcification in the glass ionomer group was a score of 3 , meaning decalcification on three of the six anterior teeth.

To examine the intra oral photos for extreme examples of decalcification, the photos were un-blinded according to cement group. After evaluating the photos for each group, the amount and appearance of decalcification is quite different for each type of cement. The composite resin group demonstrated a decalcification pattern that resembled the outline of the bracket. Decalcification was more evident near the gingival margin. Finding good examples of decalcification on multiple teeth in the glass ionomer group was difficult. The decalcification was not in a clear pattern and only appeared in small amounts (Figures 4-8).
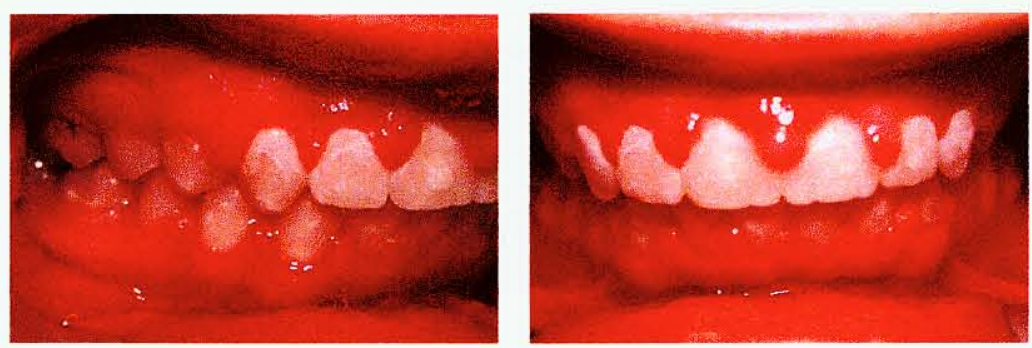

Figure 4. Patient in composite resin cement group. 

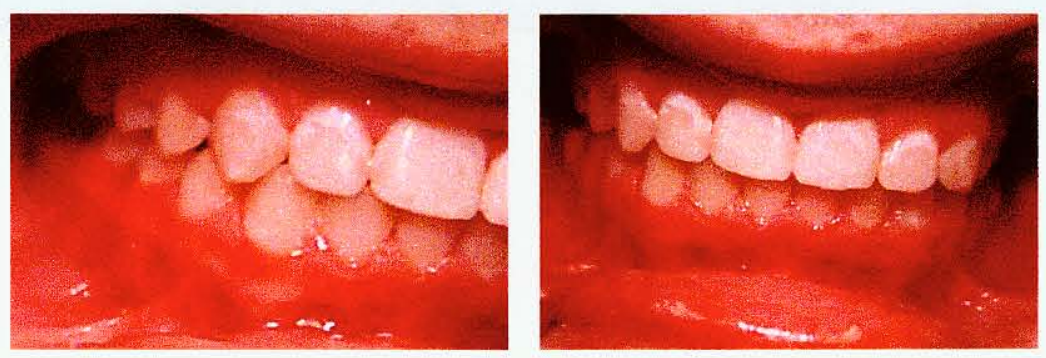

Figure 5. Patient in composite resin cement group.
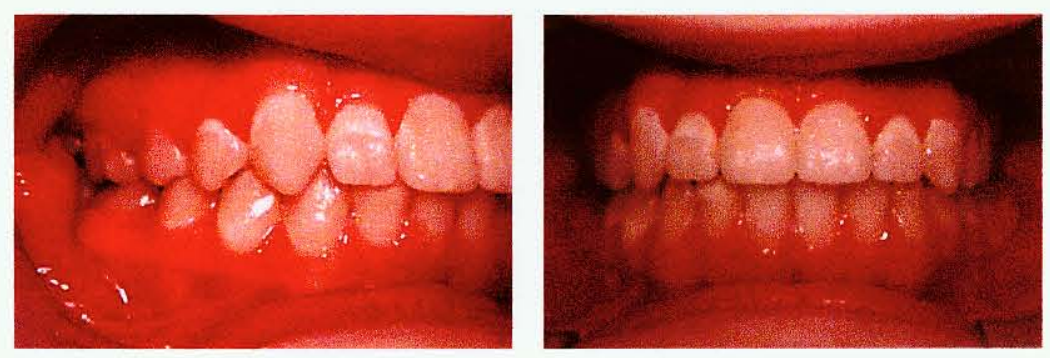

Figure 6. Patient in composite resin cement group.
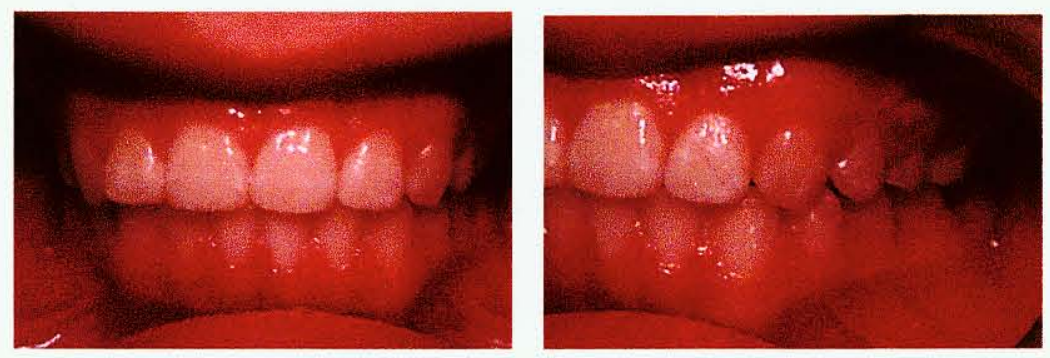

Figure 7. Patient in glass ionomer cement group.
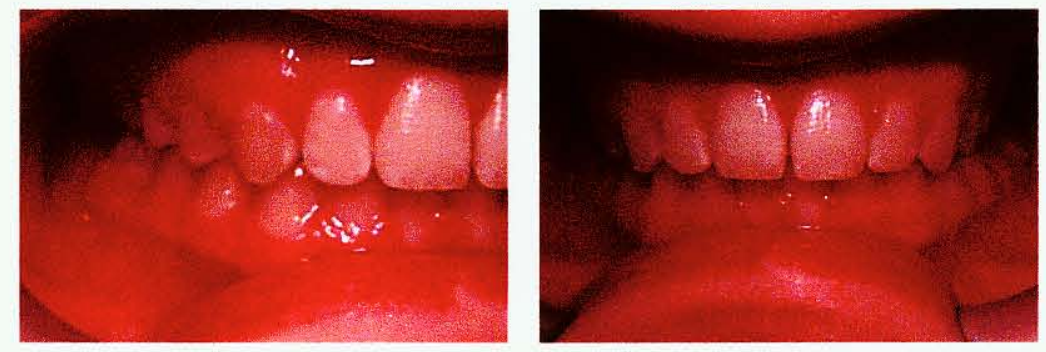

Figure 8. Patient in glass ionomer cement group. 
Figure 9 is a box plot for change in decalcification and hygiene. This box plot shows a trend towards increased decalcification with an increase of plaque on teeth during the oral hygiene exam (Table 2). All outliers were noted in the first hygiene group. Outlier \#14 with a decalcification score of 6 and a hygiene score of 1 was also an outlier with the cement type in Figure 8.

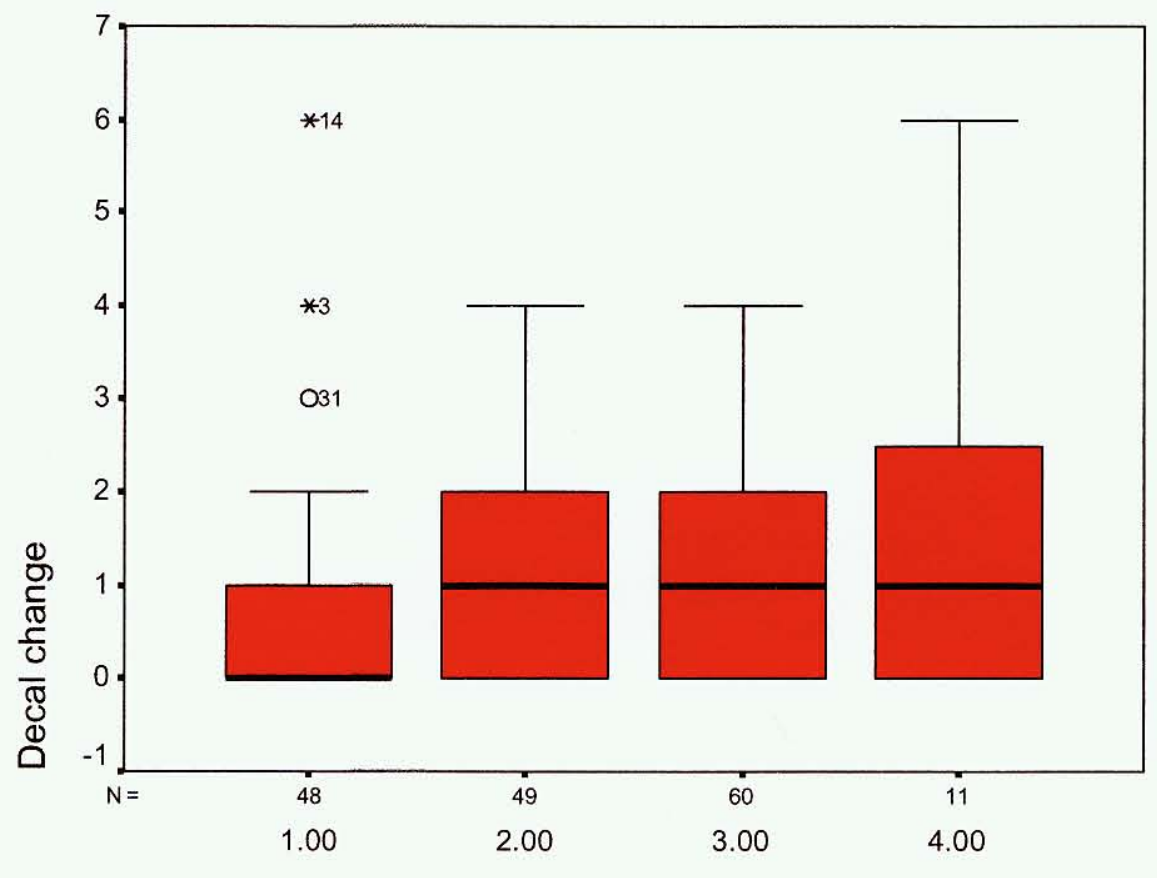

Hygiene

Figure 9. Box plot: Decal Change vs. Hygiene

Figure 10 is a box plot of change in decalcification and treatment months. In order to consolidate the data and establish meaningful results, treatment months were placed into groups. Treatment months were categorized as follows: Group 1: 0-12 months; Group 2: 13-24 months; Group 3: 25-30 months; Group 4: 31 months and 
greater (Table 7). Although there was no significant findings, there is definitely a trend for decrease in decalcification during treatment times of one year and less.

Again, there were four outliers, two of which were outliers in both hygiene and cement type.

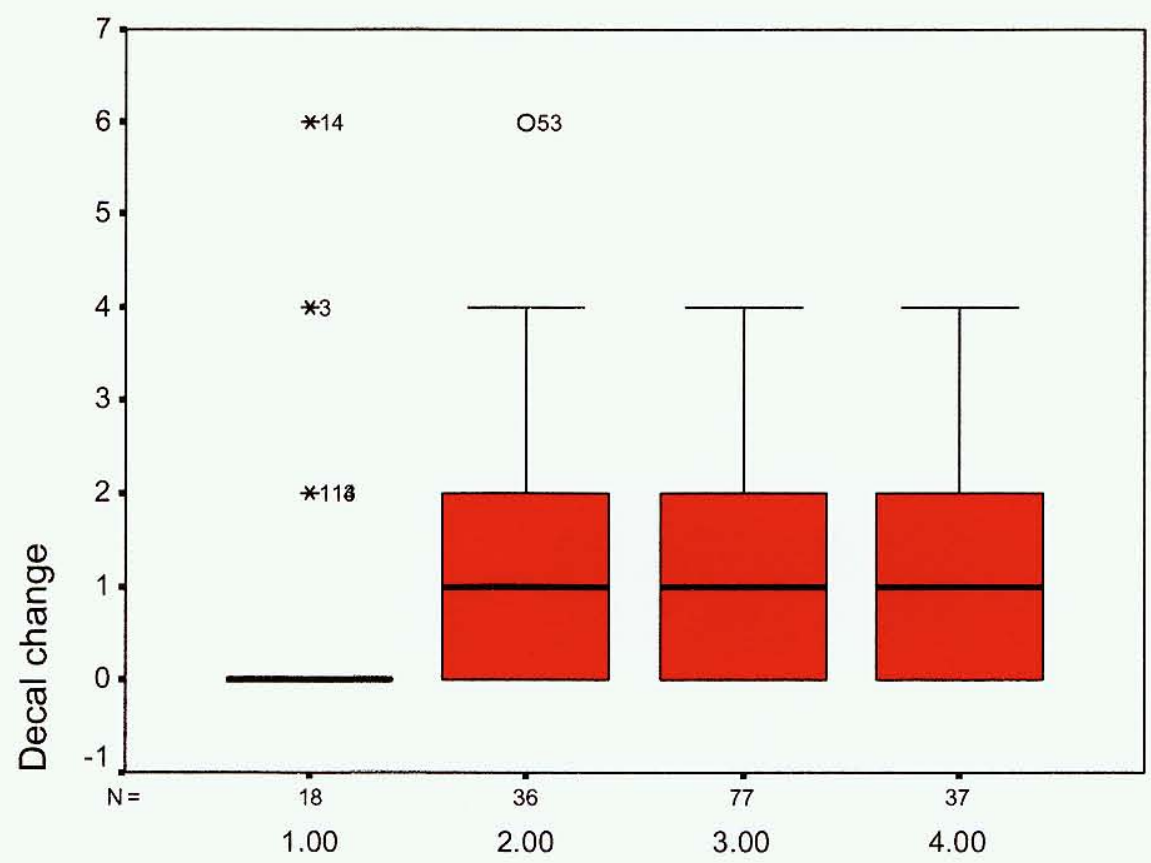

Treatment Months

Figure 10. Box plot: Decal Change vs. Treatment Months.

\section{Table 7.}

Treatment times

\begin{tabular}{|c|c|}
\hline Group & Treatment time \\
\hline 1 & $0-12$ months \\
\hline 2 & $13-24$ months \\
\hline 3 & $25-30$ months \\
\hline 4 & 31 months and greater \\
\hline
\end{tabular}


Figure 11 shows the results in a line graph of estimated marginal means of decalcification change according to type of cement and treatment time. As noted in the box plot graph for treatment time and decalcification change, for the treatment time of one year and less, there is a definite decrease in the amount of decalcification (less than one tooth on average). There is a spike in the amount of decalcification in the composite group at 13-24 months. The glass ionomer group also increases in decalcification at this point, but it is less than the 12 month amount of decalcification for the composite resin group. At all treatment times, the glass ionomer group had less decalcification than the composite resin group.

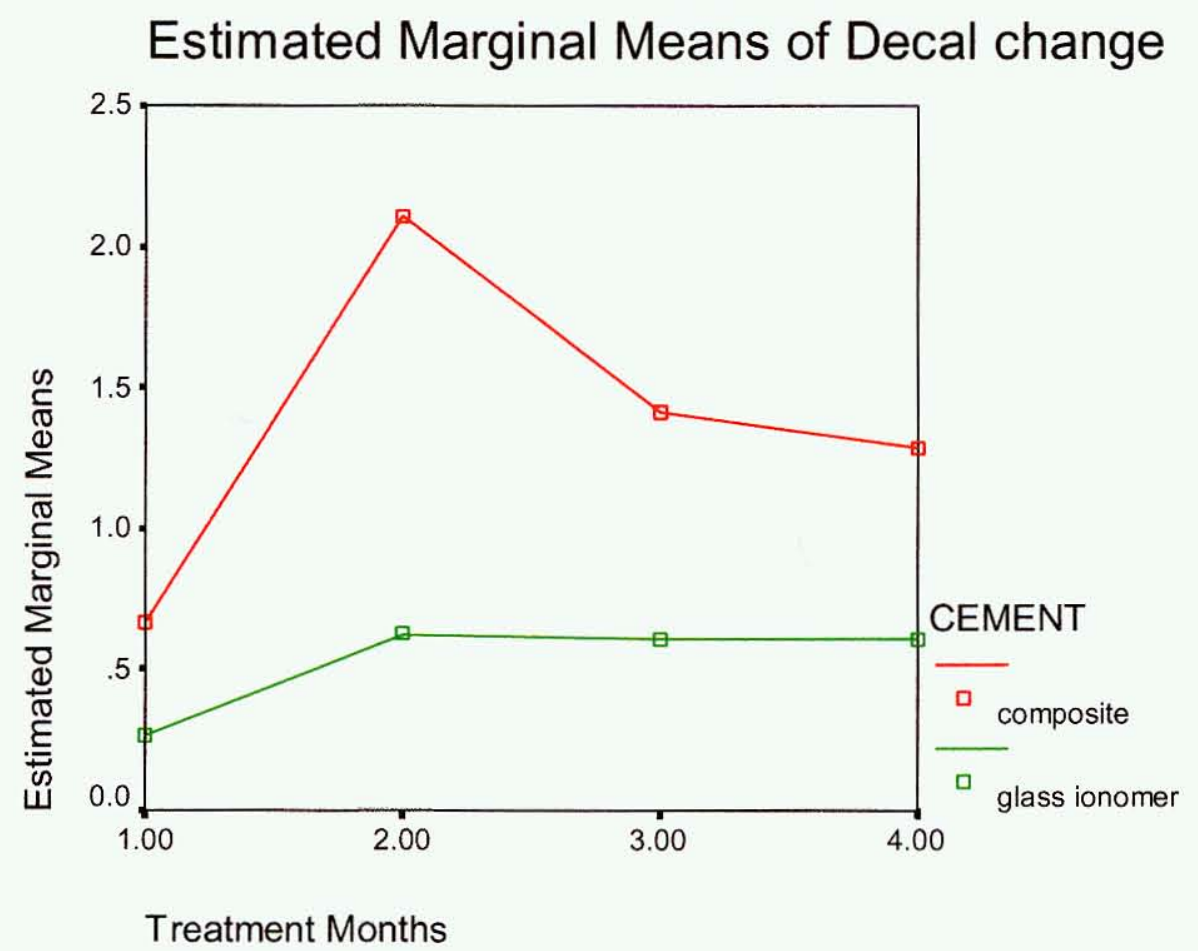

Figure 11. Line Graph: Estimated marginal means of decal change for Treatment Months and Type of Cement 
Figure 12 is a line graph showing the estimated marginal means of decal change according to type of cement and hygiene. For all levels of hygiene, the glass ionomer group demonstrated less decalcification than the composite resin group. Except for a spike in decalcification at a hygiene score of 2 with the composite resin group, both groups showed a trend for an increase in decalcification with an increase in oral hygiene scores. Both groups had smaller decalcification scores at a hygiene score of 1 .

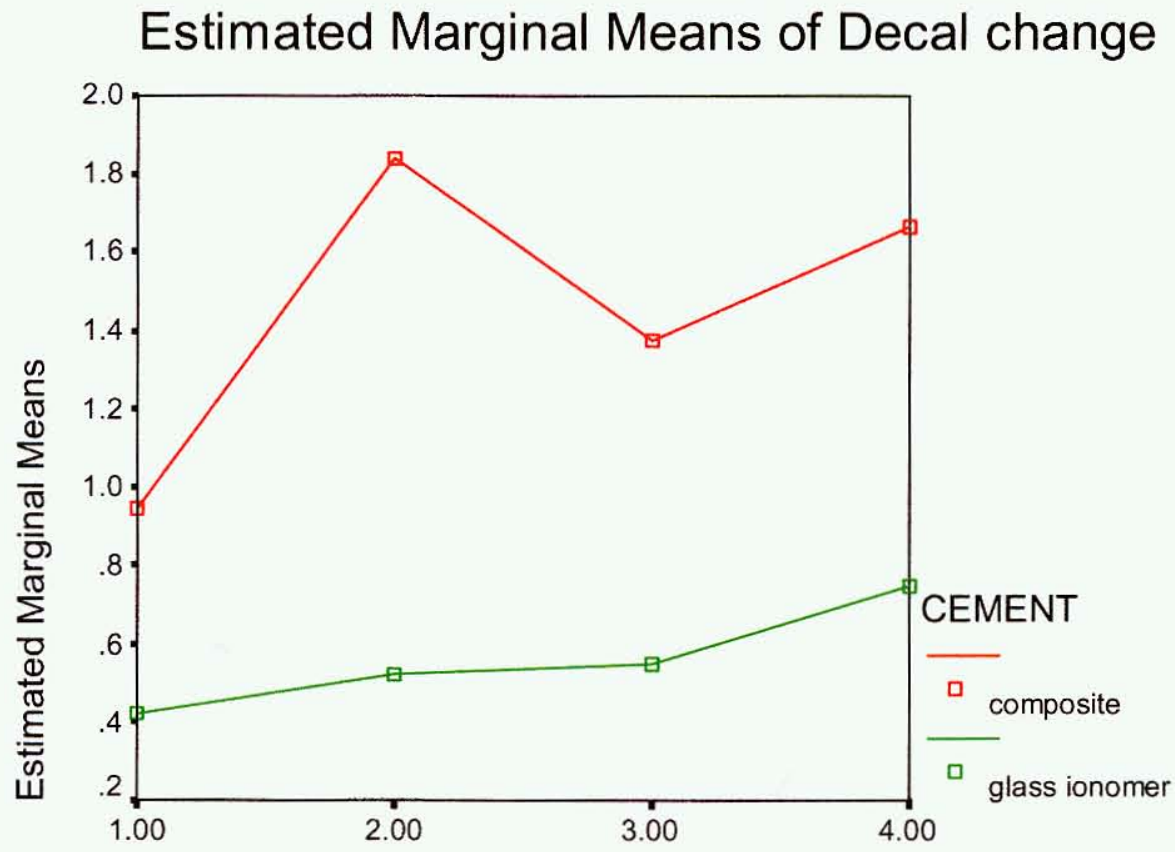

Hygiene

Figure 12. Line Graph: Estimated marginal means of decal change for Hygiene and Type of Cement 


\section{CHAPTER V}

\section{DISCUSSION}

The purpose of this study was to evaluate decalcification following orthodontic treatment using either composite resin or RMGI cements to direct bond brackets. The contribution of hygiene and treatment time to decalcification was also evaluated. The first null hypotheses of the study predicted that there would be no significant difference between the glass ionomer and composite resin cements. After analyzing the data collected, the null hypothesis was rejected. The second null hypothesis stated that there was no difference between the incidence of decalcification with varying levels of oral hygiene. After the data analysis, it is necessary to fail to reject the null hypothesis. The third null hypothesis stated that there was no difference between the incidence of decalcification with varying treatment times. After the data analysis, it is also necessary to fail to reject this null hypothesis.

In this retrospective study, a greater incidence of decalcification occurred when brackets were bonded with composite resin than with resin modified glass ionomer. This is in contrast with some past studies (Millett, Nunn, Welbury and Gordon, 1999; Gaworski et al, 1999). However, as cited previously, a major mechanism for the fluoride releasing properties of glass ionomer cements is through continual exposure to fluoride. In past studies, no protocols were in place for the recharge of fluoride. In this study, all patients were placed on a daily fluoride regimen. 
In this study, no significant difference existed between the incidence of decalcification and oral hygiene. However, as demonstrated by Figures 9 and 12, a definite trend towards an increase in decalcification occured with poor oral hygiene. One of the problems with the hygiene grading system may be a lack of calibration between observers. Six different assistants scored the oral hygiene. This is one of the inherent difficulties with retrospective studies. Future studies should focus on either reducing the number of examiners or thoroughly calibrating each examiner prior to data collection. Another problem with oral hygiene scores when evaluating the amount of plaque on the teeth is the fact that this score is based at one particular point in time. A patient with poor oral hygiene may brush well prior to the orthodontic appointment and still receive a good hygiene score. Likewise, a good brusher may have not been able to brush prior to the appointment and may receive a poor score. An example of this is the patient in Figure 10 who received an overall score of 1 although this patient clearly has poor oral hygiene and therefore was an outlier in this study.

No significant difference existed in this study between the incidence of decalcification and treatment months. This is consistent with the results of the study conducted by Gorelick et al in 1982 . However, in his study, no teeth were bonded for less than 12 months. As evident by Figures 8 and 11, a clear decrease in decalcification occurs in the group with a treatment time of 12 months and less. The glass ionomer group had a slight increase in decalcification with an increase in treatment time. This group was less affected by the increase in treatment time as compared to the composite resin group (Figure 11). This may be due to the fluoride-releasing nature of the glass ionomer cement over time when recharged continually with fluoride. 
The Pearson correlation demonstrated that the examiner was well calibrated when scoring the intraoral photos. This was the aim when designing the study and only scoring based on the presence or absence of decalcification. However, as seen by Figures 4-8, a great difference occurred in the presence of decalcification in patients bonded with composite resin versus glass ionomer. Future prospective studies should focus on evaluating the amount of decalcification on each tooth to quantitatively determine the difference in decalcification between the two groups. In a retrospective study such as this one, determining the amount of decalcification on each tooth is difficult to do based on intraoral photographs of varying quality.

With retrospective studies, many factors are out of the examiner's control. Of the 100 patients in each group, several patients transferred out of the area and were removed from the sample. The area where the private practice is located has a large military population, and therefore, transfers out of either group were considered to be random. All remaining patients in both groups were maintained in the sample regardless of the fact that the groups were uneven in number. 


\section{CHAPTER VI \\ SUMMARY AND CONCLUSIONS}

The purpose of this study was to compare the presence of decalcification following orthodontic treatment when using composite resin or RMGI cements to directly bond orthodontic brackets. The secondary purpose of this study was to examine treatment time and hygiene for any effect on decalcification. This study showed that only the type of cement was significant. Treatment time and hygiene were not significant.

The results of this investigation demonstrated that a resin modified glass ionomer cement such as Fuji Ortho can be used for orthodontic bonding to reduce decalcification around brackets when used with a fluoride rinse protocol. Past studies have shown that even newer resin modified glass ionomer cements have a weaker bond strength than traditional composite resin cements. However, these resin modified glass ionomer cements do have high enough bond strengths to be clinically acceptable (Fricker, 1998; Rix, 2000). As dental materials continue to improve, fluoride-releasing properties will continue to combine with increased strength to create cements that are superior in both aspects.

Decalcification is an early stage of dental caries, which has a mutifactorial etiology. One must remember the basics of cariology and the interrelationship between the host, substrate (diet), bacteria and time. A patient with a good diet and excellent 
oral hygiene will not be as prone to decalcification as the patient that drinks sodas all day and brushes only once a day. For the first patient, little change in decalcification would occur regardless of the type of cement used or type of fluoride regimen. The second patient would probably experience some decalcification with either cement, but the fluoride releasing properties of the RMGI would most likely reduce the severity of the decalcification.

In conclusion, this study has demonstrated that resin modified glass ionomer cements used in conjunction with daily fluoride rinse can significantly reduce the presence of decalcification around orthodontic brackets when compared with composite resin. For all levels of oral hygiene scores and treatment times, the glass ionomer group had less decalcification than the composite resin groups. Although hygiene and treatment times did not significantly affect decalcification, definite trends occurred in both areas. Future research should focus on conducting a large prospective split-mouth study including a daily fluoride rinse. Hygiene scores should be conducted by a single examiner or multiple well-calibrated examiners. Patients should be followed throughout their entire course of treatment. Decalcification is a significant problem in the orthodontic profession and researchers should continue to focus on new methods to help reduce the unsightly "white spots" that mar the final finish of an excellent occlusion. 


\section{REFERENCES}

Banks PA, Chadwick SM, Asher-McDade C, Wright JL. (2000) Fluoride-releasing elastomerics - a prospective controlled clinical trial. European Journal of Orthodontics 22 (4): 401-407.

Bishara SE, Olsen ME, Damon P, Jakobsen JR. (1998) Evaluation of a new light-cured orthodontic bonding adhesive. American Journal of Orthodontics and Dentofacial Orthopedics 114(1): 80-87.

Bishara SE, VonWald L, Laffoon JF, Jakobsen JR. (2000) Effect of changing enamel conditioner concentration on the shear bond strength of a resin-modified glass ionomer adhesive. American Journal of Orthodontics and Dentofacial Orthopedics 118(3): 311-316.

Boyd RL. (1993) Comparison of three self-applied topical fluoride preparations for control of decalcification. Angle Orthodontist 63: 25-30.

Charles, C. (1998) Bonding Orthodontic Brackets with Glass-Ionomer Cement. Biomaterials 19: 589-591.

Cook PA. (1990) Direct bonding with glass ionomer cement. Journal of Clinical Orthodontics 8: 509-511.

Coonar AK, Jones SP, Pearson GJ. (2001) An ex vivo investigation into the fluoride release and absorption profiles of three orthodontic adhesives. European Journal of Orthodontics 23(4): 417-424.

Featherstone JBD. (2003) The Caries Balance: Contributing Factors and Early Detection. Journal of the California Dental Association 21(2).

Fricker JP. (1998) A new self-curing resin-modified glass-ionomer cement for the direct bonding of orthodontic brackets in vivo. American Journal of Orthodontics and Dentofacial Orthopedics 113(4): 384-386.

Gaworski M, Weinstein M, Borislow AJ, Braitman LE. (1999) Decalcification and bond failure: A comparison of a glass ionomer and a composite resin bonding system in vivo. American Journal of Orthodontics and Dentofacial Orthopedics 116(5):518-21. 
Gorelick L, Geiger AM, Gwinnett AJ. (1982) Incidence of white spot formation after bonding and banding. American Journal of Orthodontics and Dentofacial Orthopedics 81: 93-98.

Hind V. (1999) Fluoride Mouth rinses. British Journal of Orthodontics 26(3): 242243.

Horowitz HS. (1980) Review of topical application: fluoride and fissure sealant, Journal of the Canadian Dental Association 46: 38-42.

Kusy R. (1994) Letter to the editor. American Journal of Orthodontics and Dentofacial Orthopedics 106(2):17A.

Mattingly JR, Sauer GJ, Yancey JM, Arnold RR. (1984) Enhancement of Streptococcus mutans colonization by direct bonded orthodontic appliances. Journal of Dental Research 62: 1209-1211.

Meehan MP, Foley TF, Mamandras AH. (1999) A comparison of the sheer bond strengths of two glass ionomer cements. American Journal of Orthodontics and Dentofacial Orthopedics 115(2):125-147.

Miguel JAM, Almeida MA, Chevitarese O. (1995) Clinical comparison between glass ionomer cement and a composite for direct bonding of orthodontic brackets. American Journal of Orthodontics and Dentofacial Orthopedics 107(5): 484-487.

Millet DT, Nunn JH, Welbury RR, Gordon PH. (1999) Decalcification in relation to brackets bonded with glass ionomer cement or a resin adhesive. Angle Orthodontist . 69(1): 65-70.

Newman RA, Newman GV, Sengupta A. (2001) In Vitro Bond Strengths of Resin modified Glass Ionomer Cements and Composite Resin Self-cure Adhesives: Introduction of an Adhesive System with increased Bond Strength and Inhibition of Decalcification. Angle Orthodontist 71(4): 312-316.

Norevall LI, Marcusson A, Persson M. (1996) A clinical evaluation of a glass ionomer cement as an orthodontic bonding adhesive compared with an acrylic resin. European Journal of Orthodontics 18(4): 373-384.

O'Reilly MM, Featherstone JDB. (1987) Demineralization and remineralization around orthodontic appliances: An in vivo study. American Journal of Orthodontics and Dentofacial Orthopedics 92: 33-40.

Rix D, Foley TF, Mamandras A. (2001) Comparison of bond strength of three adhesives: Composite resin, hybrid GIC, and glass-filled GIC. American Journal of Orthodontics and Dentofacial Orthopedics 119 (1):36-41. 
Silverstone LM, Hicks MJ, Featherstone MJ. (1985) Oral fluid contamination of etched

enamel surfaces: An SEM study. Journal of the American Dental Association 110:329-32.

Sturdevant CM, Roberson TM, Heymann HO, Sturdevant JR. (1995) The Art and Science of Operative Dentistry. Mosby - Year Book, Inc. St. Louis, Missouri.

Trimpeneers LM, Dermaut LR. (1996) A clinical evaluation of the effectiveness of a fluoride-releasing visible light-activated bonding system to reduce demineralization around orthodontic brackets. American Journal of Orthodontics and Dentofacial Orthopedics 110: 218-222.

Vorhies AB, Donly KJ, Staley RN, Wefel JS. (1998) Enamel demineralization adjacent to orthodontic brackets bonded with hybrid glass ionomer cements: an in vitro study. American Journal of Orthodontics and Dentofacial Orthopedics 114(6): 668-64. 


\title{
CURRICULUM VITAE
}

\section{Jennifer L. Butterfoss \\ 501 South Preston \\ School of Dentistry-Orthodontics \\ Louisville, KY 40292 \\ Jlbutt03@gwise.louisville.edu}

\section{Personal Information}

\author{
Date of Birth: June 12, 1976 \\ Place of Birth: Philadelphia, PA \\ Marital Status: Single \\ Citizenship: U.S.A.
}

\section{Education}

1998-2002 Virginia Commonwealth University

School of Dentistry

P.O. Box 980566

Richmond, VA 23298-0566

Degree: Doctor of Dental Surgery - Magna Cumlaude

1994-1998 College of William and Mary

P.O. Box 8795

Williamsburg, VA 23187

Degree: Bachelor of Business Administration

Major: Business/Marketing Minor: Chemistry

\section{$\underline{\text { Activities }}$}

Virginia Commonwealth University

\begin{tabular}{|c|c|}
\hline \multirow{3}{*}{$\begin{array}{l}2001-2002 \\
2000-2001\end{array}$} & VCU Dental School Admissions \\
\hline & Class Secretary \\
\hline & Social Chair, Psi Omega Fratemity \\
\hline $1999-2000$ & $\begin{array}{l}\text { ASDA Representative } \\
\text { Pros Coop Chair }\end{array}$ \\
\hline $999-2$ & Member of Psi Omega Fr \\
\hline 1998-19 & Class Academic Committee Chair \\
\hline
\end{tabular}

\section{College of William and Mary}

1997-1988 National Kappa Delta Chapter Officer Williamsburg Youth Soccer Coach

1996-1998 Student Library Advisory Committee Gallery Players, Flute Soloist 


$\begin{array}{ll}1996-1997 & \text { Homecoming Chair } \\ 1995-1998 & \begin{array}{l}\text { Orientation Aid } \\ \text { Operation Smile }\end{array} \\ & \text { William and Mary Club Soccer } \\ 1994-1998 & \text { Public Relations for Kappa Delta }\end{array}$

\section{Employment}

Summer 1999

Summer 1997

Winter 1997-1998

\section{Research}

1999-2000

1997-1998

\section{$\underline{\text { Presentations }}$}

April 200

1998-2003

2002-2003

1996-1998

1997-1998

\section{Honors and Awards}

2002

1999-2001

1996
A.D. Williams Research Fellow
Department of Orthodontics
Virginia Commonwealth University
School of Dentistry
Richmond, VA 23298
Dental Assistant/ Intern
Office of Drs. Booker and Morgan
Yorktown, VA 23692
Sterilization/ Intern
Office of Dr. Butterfoss
Yorktown, VA 23692

Panoramic Radiography: A Comparison of Digital Charged Couple Receptors and Conventional Silver Halide Film

QOL Assessment of William and Mary Student Body
Digital Panoramic Radiography

Clinic Day

VCU School of Dentistry

American Association of Orthodontics American Student Dental Association Omicron Kappa Upsilon BBA Society

American Marketing Association

Omicron Kappa Upsilon

Deans List

Virginia Commonwealth University - School of Dentistry

Deans List

College of William and Mary 